\title{
SCHOOL-BASED FLOURIDE MOUTH RINSE (S-FMR) SEBAGAI UPAYA PENCEGAHAN KARIES PADA ANAK: SEBUAH TINJAUAN PUSTAKA
}

\section{Pratitis Widi Seno*, Ambar Delfi Mardiunti", Dewi Sartieka Putri", Irma Khoerunisa*, Fitri Diah Oktadewi*}

*Program Profesi Dokter Gigi, Jurusan Kedokteran Gigi, Fakultas Kedokteran, Universitas Jenderal Soedirman

${ }^{*}$ Departemen IImu Kedokteran Gigi Masyarakat dan Pencegahan, Jurusan Kedokteran Gigi, Fakultas Kedokteran, Universitas

Jenderal Soedirman.

Correspondence : Pratitis Widi Seno, Program Profesi Dokter Gigi, Jurusan Kedokteran Gigi, Fakultas Kedokteran, Universitas Jenderal Soedirman

Email : widi.pratitis37@gmail.com

\section{Keywords:}

Caries, Flouride, School based fluoride mouth rinse

\section{ABSTRACT}

Background: Dental caries is an infectious microbial disease that begins as demineralization of an inorganic portion of tooth, followed by the destruction of organic parts, leading to cavity formation. Fluoride helps to prevent caries which can be administered systematically or topically. Fluoride mouth rinse has been used in school program to prevent caries.

Method: This article aim is to describe the effectiveness of school-based fluoride mouth rinse (S-FMR) as one of the effective methods to prevent caries on children.

Discussion: The School-based Fluor Mouth Rinse (S-FMR) program or gargling using fluoride in schools is the use of fluoride as a mouth rinse for children aged 6-18 years conducted in the school environment. Several studies have shown that S-FMR can reduce the prevalence of caries.

Conclusion: S-FMR is considered effective in preventing caries due to the simple method, cost-effectiveness, time efficiency, and easily undertaken by the teacher's supervision.

\section{PENDAHULUAN}

Karies gigi merupakan keadaan patologis yang disebabkan oleh beberapa faktor dan menyebabkan rusaknya jaringan keras gigi sehingga menimbulkan komplikasi lokal maupun general. ${ }^{1}$ Hasil Riskesdas tahun 2018 menunjukkan prevalensi indeks DMFT Indonesia mengalami peningkatan indeks DMF-T menjadi >6 dari Hasil Riskesdas tahun 2013 dengan indeks DMF-T sebesar 4,6 dan meningkat seiring dengan pertambahan usia., ${ }^{2,3}$ Hasil Riskesdas tahun 2018 menunjukkan prevalensi karies di Indonesia pada tahun 2018 mencapai 45,3\%. ${ }^{2}$ Kondisi tersebut menunjukkan bahwa prevalensi karies di Indonesia masih tinggi. Global Goals for Oral Health 2020 adalah indeks DMF-T kurang dari 1 pada anak usia 12 tahun dan peningkatan angka bebas karies pada gigi sulung anak usia 6 tahun, namun hal ini belum tercapai di Indonesia. Tingginya angka prevalensi karies tersebut membuat karies gigi menjadi salah satu masalah kesehatan gigi yang perlu diperhatikan dan memerlukan tindakan pencegahan secara masal. ${ }^{4}$

Pencegahan karies dapat dilakukan menggunakan fluoride. ${ }^{5}$ Beberapa penelitian menunjukkan bahwa fluoride dengan kadar rendah yang dipertahankan dalam rongga mulut merupakan tindakan pencegahan karies terbaik. ${ }^{1}$ Fluoride efektif dalam mencegah karies karena fluoride berfungsi dalam beberapa cara. Fluoride dalam saliva dan plak berperan menghambat proses demineralisasi dan menginisasi proses remineralisasi pada lesi awal karies. Fluoride dapat mengganggu proses glikolisis bakteri dan fluoride dalam konsentrasi tinggi memiliki efek bakterisida pada bakteri kariogenik dan bakteri yang lain. ${ }^{6}$ Bentuk fluoride yang sering dijumpai pada program pencegahan karies biasanya 
berupa pemberian tablet fluoride secara oral, aplikasi topikal fluoride pada permukaan gigi, penggunaan pasta gigi berfluoride, garam berfluoride, obat kumur berfluoride, fluoridasi air minum, serta fluoride dalam makanan dan minuman. ${ }^{7}$

Penelitian yang dilakukan oleh Divaris di North Carolina membuktikan bahwa anak yang tidak pernah diberikan tambahan konsumsi fluoride mempunyai resiko mengalami karies gigi empat kali lebih tinggi. ${ }^{8}$ Pemberian fluoride utamanya diberikan kepada anak usia sekolah. Sekolah merupakan lingkungan yang efektif dalam melakukan tindakan preventif karies pada anak, karena penyampaian pendidikan kesehatan gigi dan mulut serta penerapan kegiatan menyikat gigi bersama di dalam kelas lebih diterima oleh anak. ${ }^{9}$ Salah satu penelitian di Jepang yang dilakukan oleh Matsuyama dkk. menggambarkan bahwa terdapat ketimpangan prevalensi karies antar provinsi di Jepang. Ketimpangan terjadi akibat perbedaan latar belakang warga, pendidikan, akses menuju dokter gigi, faktor ekonomi dan lingkungan sosial. Matsuyama dkk. menyatakan bahwa ketimpangan angka prevalensi karies disebabkan oleh penyebaran intervensi yang kurang efektif. Intervensi yang dapat digunakan untuk mengurangi ketimpangan prevalensi karies adalah intervensi sosial. ${ }^{10}$ Salah satu contoh intervensi sosial adalah S-FMR. Program S-FMR merupakan strategi pencegahan karies gigi di tingkat sekolah dengan memberikan fluoride topikal secara berkala dalam jangka waktu panjang. ${ }^{11,12}$ Hasil penelitian yang dilakukan oleh Matsuyama dkk. meningkatnya penggunaan S-FMR sebanyak $1 \%$ dapat menurunkan nilai DMF-T sebesar 0,11 dan SFMR lebih efektif pada daerah dengan nilai DMF$T$ yang tinggi pada anak usia 3 tahun. ${ }^{10}$
Beberapa penelitian menunjukkan bahwa SFMR mampu menurunkan resiko kejadian karies seperti penelitian di Sarawak dan North Carolina. ${ }^{8,13}$ Chen dkk. menunjukkan bahwa penggunaan S-FMR mampu menurunkan resiko munculnya karies sebanyak 0,52 kali lebih rendah dibandingkan dengan anak yang tidak melakukan S-FMR, ${ }^{13}$ sedangkan Divaris dkk. menyatakan bahwa pemanfaatan S-FMR dalam jangka panjang dapat menurunkan prevalensi karies pada masa gigi desidui dan masa gigi bercampur. $^{8}$

Indonesia telah melakukan banyak upaya pencegahan karies seperti penyuluhan kesehatan gigi dan mulut, pemberian topikal fluoride, serta pengadaan program Usaha Kesehatan Gigi Sekolah (UKGS). ${ }^{14,15}$ Pedoman pelaksanaan program UKGS yang diterbitkan oleh Kementerian Kesehatan Republik Indonesia (Kemenkes RI) menyarankan beberapa program kesehatan gigi berbasis sekolah seperti kegiatan sikat gigi bersama di sekolah menggunakan pasta gigi berfluoride, topikal aplikasi casein phosphopeptide-amorphous calcium phosphate (CPP-ACP), fluoridasi air minum, pelatihan kesehatan gigi dan mulut untuk guru, serta penyuluhan kepada anak mengenai kesehatan gigi dan mulut. ${ }^{15}$ Jurnal ini bertujuan untuk memaparkan efektivitas program S-FMR sebagai upaya pencegahan karies pada anak.

\section{TINJAUAN PUSTAKA}

\section{Fluoride}

Fluoride atau fluor merupakan zat mineral yang digunakan sebagai bahan yang efektif mencegah terjadinya karies gigi dengan membuat lapisan email tahan terhadap kerusakan yang disebabkan pelarutan email oleh zat asam. ${ }^{16}$ Fluor banyak ditemukan di batuan vulkanik, pemakaian pupuk, penanaman industri 
pembakaran batubara dan air. Air laut mengandung fluor 1,2-1,5 ppm, air bersih mengandung fluor kurang lebih 0,3 ppm dan air minum sekitar 0,5-0,7 ppm. ${ }^{17}$ Struktur kristal fluor lebih tahan terhadap asam sehingga dapat menghambat karies. ${ }^{18}$ Fluor dapat diendapkan pada jaringan keras gigi seperti $\mathrm{CaF}_{2}$, terikat pada mukosa oral dan diserap oleh plak gigi. ${ }^{19}$ Penelitian menunjukkan bahwa ion fluor yang bebas dalam larutan di sekitar kristal email gigi memiliki peran yang jauh lebih penting dalam pencegahan karies. ${ }^{17}$ Fluor memiliki efek penghambatan langsung pada aktivitas glikolisis bakteri kariogenik dimana terjadi pemecahan metabolik glukosa dan gula lainnya melepaskan energi dalam bentuk ATP. ${ }^{6}$

Fluoride mempunyai kemampuan untuk bereaksi dengan permukaan email gigi dalam membentuk kalsium fluoride dan fluorapatit, sehingga membuat permukaan email lebih tahan terhadap demineralisasi dan kerusakan. ${ }^{17}$ Fluoride yang bereaksi dengan membentuk kalsium fluoride dan fluorapatit akan meningkatkan meneralisasi email dan membuat email lebih resisten terhadap serangan asam. ${ }^{6}$ Para ahli telah mengembangkan berbagai metode penggunaan fluoride yang dibedakan menjadi metode perorangan dan kolektif. Penggunaan fluoride ini dapat dilakukan dengan dua cara yaitu sistemik dan lokal. ${ }^{18}$ Pemberian fluoride secara sistemik dilakukan dengan fluoridasi air minum dan pemberian tablet fluor, sedangkan pemberian secara topikal dapat berupa menyikat gigi dengan pasta gigi berfluoride serta aplikasi topikal dengan larutan fluoride. Indikasi dan kontra indikasi penggunaan fluor pada anak menurut Donley tahun 2003 meliputi anak berusia lebih dari 5 tahun, anak dengan resiko karies sedang-tinggi, anak dengan gigi yang sensitif, anak yang mengalami kelainan motorik, dan anak dengan perawatan ortodontik. Kontra indikasi penggunaan fluoride pada anak adalah anak dengan resiko karies rendah, anak yang tinggal di kawasan air minum yang cukup mengandung fluor, dan anak dengan kavitas besar terbuka. ${ }^{20}$

Bentuk pemberian fluoride secara topikal terdiri dari pasta gigi dan aplikasi topikal fluoride. Aplikasi opikal ini dapat berupa fluoride varnish, fluoride gel, fluoride foam, slow-release fluoride devices, fluoride mouthrinse, dan silver-diamine fluoride. ${ }^{21}$ Bentuk aplikasi tersebut dibagi menjadi dua, yang dilakukan oleh dokter gigi (fluoride varnish, sfluoride gel, fluoride foam, slow-release fluoride devices, silver-diamine fluoride) dan dilakukan oleh pasien sendiri (obat kumur dan pasta gigi). ${ }^{4}$ Flouride mouth rinse (FMR) merupakan salah satu bagian dari strategi pencegahan karies pada populasi dengan resiko tinggi yang disarankan seperti orang dengan prevalensi karies tinggi dan pengguna alat orthodontik. Produk ini mengandung fluoride sebanyak 100-500 ppm dan digunakan 1 atau 2 kali sehari. ${ }^{22}$ Fluoride mouth rinse dengan dosis fluoride 900 ppm biasa digunakan dalam program S-FMR yang dilakukan seminggu atau dua minggu sekali yang dilakukan pada daerah dengan prevalensi karies tinggi namun tidak mendapatkan program fluoridasi air minum. ${ }^{4}$ Penggunaan obat kumur berfluoride tidak disarankan digunakan pada anak dengan usia dibawah 6-7 tahun karena belum mampu mengeluarkan sisa kumur dari dalam mulut. ${ }^{21}$ Penelitian menunjukkan bahwa penggunaan FMR tidak menyebabkan toksisitas akut pada anak. Penggunaan FMR pada daerah yang telah menggunakan pasta gigi berfluoride dengan baik dapat membantu menurunkan prevalensi karies dengan waktu pengguaannya tidak dilakukan bersamaan dengan menyikat gigi. ${ }^{10}$ Obat kumur 
yang mengandung fluor dapat menurunkan karies sebanyak $20-50 \%{ }^{6}$

Pemberian fluoride secara sistemik dapat berupa fluoridasi air minum, pemberian garam berfluoride, dan susu berfluoride. Fluoridasi air dikatakan efektif menurunkan angka karies hingga $20-40 \%$, khususnya bagi masyarakat yang kesulitan akses periksa gigi rutin. Hasil systematical review menunjukkan bahwa penggunaan air minum berfluoride menurunkan prevalensi karies pada gigi desidui maupun permanen. Penggunaan metode fluoridasi air minum mampu menyentuh seluruh populasi sehingga seluruh strata sosial dapat terkena dampak oleh fluoridasi air minum. Program ini disarankan oleh WHO dan FDI Worl Dental Federation namun ternyata tidak semua negara melaksanakan dan jarang ditemukan pada daerah perdesaan. Dosis fluoride yang disarankan pada fluoridasi air minum adalah 0,5$1 \mathrm{mg} / \mathrm{L}$ dan ini akan bergantung pada suhu daerah dan kebudayaan gaya hidup daerah tersebut. Fluoridasi air minum memliki efek samping berupa fluorosis apabila penggunaan dan dosis yang digunakan tidak sesuai. Sebagai contoh, di negara Hongkong, air minum berfluoride dengan kadar $0,8 \mathrm{mg} / \mathrm{L}$ menimbulkan fluorosis pada anak. ${ }^{6}$

\section{School-based Fluoride Mouth Rinse (S-FMR)}

Program S-FMR atau berkumur menggunakan fluor di sekolah merupakan penggunaan fluor sebagai bahan kumur pada anak usia 6-18 tahun di sekolah yang bertujuan untuk mengurangi angka karies gigi. Program berbasis sekolah seringkali lebih efektif karena anak akan bersekolah setiap hari sehinga dapat di jadwalkan untuk melakukan kumur fluor setiap seminggu atau dua minggu sekali. ${ }^{23}$ S-FMR memiliki kelebihan karena dapat dilakukan dalam waktu yang singkat dan mudah dilakukan oleh anak anak. Kelebihan lain dari S-FMR adalah dosis yang digunakan dalam S-FMR cenderung rendah namun diberikan dalam jangka waktu tertentu. Pemberian fluoride dalam dosis rendah secara berkala dinilai lebih efektif mencegah karies dibandingkan dengan pemberian fluoride dosis tinggi namun jarang. ${ }^{24}$ Penggunaan FMR dilakukan dengan waktu kurang dari 5 menit. ${ }^{25}$ Menurut penelitian yang dilakukan di Sarawak penggunaan FMR dengan kadar fluoride 0,2 \% mampu menurunkan resiko karies sebanyak 0,52 kali dibandingkan dnegan sekolah yang tidak menggunakan FMR. ${ }^{13}$

Program ini utamanya dilakukan pada anak usia sekolah yang memiliki resiko tinggi karies. Sekolah dipilih menjadi salah satu populasi yang diberikan intervensi karena di sekolah intervensi tidak akan dipengaruhi oleh ekonomi, sosial, serta pendidikan. Semua siswa mendapatkan porsi intervensi yang sama dan dapat dilaksanakan secara rutin. S-FMR meningkatkan kesehatan gigi anak sekolah terlepas dari status sosial ekonomi mereka, dan lebih efektif untuk anak sekolah dengan status gigi buruk. ${ }^{10} \mathrm{~S}$-FMR membantu sekolah dalam melakukan pencegahan secara alternatif kontrol karies. Manfaat dari berkumur dengan fluor adalah memperkuat lapisan luar dari enamel gigi dan fluor tidak tertelan. S-FMR tentunya bukan dimaksudkan sebagai ganti dari menyikat gigi sehingga anak tetap harus melakukan sikat gigi minimal dua kali sehari. Berkumur dengan fluor dilakukan selama satu menit dan setelahnya tidak boleh makan dan minum selama 30 menit. ${ }^{13}$

Program S-FMR ini lebih mudah diterapkan karena biaya yang rendah, cara yang sederhana, waktu yang singkat serta dapat diawasi oleh guru di sekolah. Penelitian membuktikan S-FMR sebagai salah satu alternatif fluoridasi air dapat 
menurunkan angka kejadian karies 30\%-35\% pada anak beresiko tinggi. ${ }^{4}$ Bahan yang digunakan dalam S-FMR pada umumnya adalah larutan $\mathrm{NaF} \quad 0,2 \% .{ }^{26}$ Hiremath mengatakan bahwa FMR dapat dilakukan dengan melarutkan bubuk $\mathrm{NaF}$ sebanyak 2 gram kedalam 1 liter air, ${ }^{24}$ namun Joseph menyebutkan bahwa terdapat beberapa jenis dan dosis bahan yang dapat digunakan dapat dilihat pada Tabel 1 sebagai berikut ${ }^{4}$ :

Tabel 1. Bahan dan dosis $\mathrm{FMR}^{4,24}$

\begin{tabular}{lccl}
\multirow{2}{*}{$\begin{array}{l}\text { Sumber } \\
\text { Flouride }\end{array}$} & \multicolumn{2}{c}{ Dosis } & Frekuensi yang \\
\cline { 2 - 3 } & $\%$ & $\mathrm{ppm}$ & direkomendasikan \\
\hline $\mathrm{NaF}$ & 0,20 & 900 & 1 minggu sekali \\
\hline $\mathrm{NaF}$ & 0,02 & 100 & 2 hari sekali \\
\hline $\mathrm{NaF}$ & 0,05 & 225 & Setiap hari \\
\hline $\mathrm{APF}$ & 0,02 & 200 & Setiap hari \\
\hline $\mathrm{SnF}_{2}$ & 0,10 & 243 & Setiap hari \\
\hline
\end{tabular}

Pelaksanaan S-FMR dilakukan dengan menyiapkan larutan fluoride kemudian membagikan kepada siswa larutan fluoride kepada siswa dalam gelas kumur sebanyak 5-10 $\mathrm{mL}$. Kemudian siswa diberikan pemahaman mengenai tata cara proses berkumur menggunakan fluor di sekolah sebagai berikut ${ }^{24}$ :

1. Siswa dijadwalkan untuk berkumur setiap minggu pada hari yang sama

2. Air kumur di takar pada gelas kumur yang sama bagi setiap siswa

3. Instruksikan siswa untuk berkumur selama 1-2 menit dan jangan ditelan, kemudian air setelah kumur dikembalikan pada gelas kumur dan diamati apakah terdapat perbedaan volume air.

4. Apabila terdapat perbedaan volume air, maka siswa diberikan susu.

5. Instruksikan siswa untuk tidak makan dan minum selama 30 menit

\section{PEMBAHASAN}

Penggunaan fluor secara luas telah menjadi faktor utama dalam penurunan prevalensi dan tingkat keparahan karies gigi berbagai negaranegara maju. ${ }^{20}$ Tindakan pencegahan yang dimulai sedini mungkin dibutuhkan agar tidak terjadi peningkatan prevalensi karies. Salah satu upaya untuk mencegah dan mengurangi proses karies adalah aplikasi fluor. Fluor merupakan elemen kimia ionik yang berikatan dengan hidroksiapatit akan berubah menjadi fluor apatit dengan sifat tahan asam. ${ }^{19}$ Mekanisme fluor mencegah dan mengurangi karies melalui 3 aksi yaitu meningkatkan proses remineralisasi, mengurangi demineralisasi, menghambat glikolosis dan mengurangi produksi asam bakteri karies. ${ }^{1}$

Penggunaan fluor dapat diberikan secara sistemik maupun secara topikal. Secara sistemik dapat dilakukan dengan pemberian tablet fluor dan melalui sumber air minum. Penelitian melaporkan pemberian fluor secara topikal dapat dilakukan dengan pemberian fluor pada gigi dengan cara pengulasan pada seluruh permukaan gigi dan berkumur-kumur dengan larutan fluor. ${ }^{16}$ Sediaan fluor topikal dapat berupa obat kumur berbasis sodium dengan kandungan fluor $0.02 \%$ (NaF), $0.044 \%$ (APF), atau $0.05 \%$ $(\mathrm{NaF}){ }^{19}$ Pemberian fluor pada anak dapat dilakukan melalui program Usaha Kesehatan Gigi Sekolah (UKGS). ${ }^{15}$

Usaha Kesehatan Gigi Sekolah (UKGS) adalah upaya memelihara dan meningkatkan kesehatan gigi dan mulut seluruh peserta didik di sekolah melalui pendidikan kesehatan, pelayanan kesehatan gigi dan mulut serta pembinaan lingkungan kehidupan sekolah sehat. ${ }^{15}$ Upaya kesehatan perorangan pada UKGS berupa intervensi individu pada peserta didik yang membutuhkan perawatan kesehatan 
gigi dan mulut yang dapat dilakukan meliputi: surface protection, fissure sealant,scalling, penumpatan dengan metode ART (Atraumatic Restorative Treatment), pencabutan gigi sulung yang sudah goyang dan aplikasi flour atau kumur-kumur dengan larutan yang mengandung flour dapat dilaksanakan di sekolah. ${ }^{14}$ Penelitian yang dilakukan di Bangladesh menyebutkan bahwa edukasi kesehatan mulut berbasis sekolah dapat meningkatkan pengetahuan, sikap, dan kebiasaan siswa untuk menjaga kesehatan gigi dan mulut. ${ }^{27}$

Program S-FMR merupakan salah satu program UKGS dari buku panduan WHO yang dilakukan selama 3 bulan dan dilakukan evaluasi setelahnya. Pengawasan dalam program S-FMR ini dapat dilakukan oleh dokter gigi maupun langsung oleh guru di sekolah. ${ }^{21}$ S-FMR telah dirancang sejak tahun 1980-an sebagai salah satu alternatif fluoridasi air ke masyarakat. ${ }^{28}$ Penelitian sejak tahun 1990-an membuktikan bahwa tingkat karies (DMF-T/dmf-t) mengalami penurunan pada siswa sekolah yang melakukan prosedur S-FMR. ${ }^{25}$ Penelitian yang dilakukan oleh Horowitz dan Fraiser menunjukkan bahwa program SMFR pada daerah yang tidak berfluoridasi untuk siswa usia 6-12 tahun menunjukan hasil penurunan resiko karies hingga 30\%-35\%. ${ }^{4}$ Program S-FMR ini lebih mudah diterapkan karena biaya yang rendah, cara yang sederhana, waktu yang singkat serta dapat diawasi oleh guru di sekolah. ${ }^{9}$ Program SFMR ditujukan pada sekolah yang mayoritas siswanya tidak memiliki akses untuk mendapatkan air minum berfluor, pendapatan orang tua rendah, prevalensi karies tinggi, serta sulit mendapatkan akses ke fasilitas kesehatan. ${ }^{21,28}$

Program S-FMR merupakan salah satu program intervensi kesehatan dengan pendekatan populasi.29 Intervensi kesehatan dengan pendekatan populasi memiliki kelebihan tidak dipengaruhi oleh faktor sosioekonomi. Penelitian yang dilakukan oleh Hutami dkk. menunjukkan bahwa semakin tinggi pendapatan orang tua maka semakin rendah nilai DMF-T anak. Keluarga dengan pendapatan rendah biasanya mengalami kesulitan untuk memenuhi kebutuhan pokok keluarga, sehingga kesadaran untuk memenuhi kebutuhan kesehatan akan menurun. Kondisi ini menjadikan masyarakat dengan sosioekonomi rendah menjadi populasi resiko tinggi. ${ }^{30}$ Keluarga dengan keadaan sosioekonomi tinggi menjadi populasi dengan resiko karies rendah karena sudah terpenuhi kebutuhan dasar. Kondisi ini membuat keluarga dengan sosioekonomi tinggi cenderung akan lebih mudah untuk menerima informasi tentang pengetahuan dan berdampak pada perhatian terhadap kesehatan diri dan keluarganya. ${ }^{31}$

Program pencegahan karies yang ditujukan pada individu seperti penggunaan pasta gigi berfluoride lebih efektif pada populasi dengan resiko rendah. ${ }^{32}$ Namun pada populasi dengan resiko tinggi tidak begitu memberikan efek dengan baik. Populasi dengan resiko rendah telah memiliki kebiasaan oral hygiene yang baik dan menggunakan pasta gigi berfloride dengan optimal. Kondisi sosio-kultural pada populasi rasio rendah cukup mendukung perubahan gaya hidup sehingga masyarakat telah memiliki kesadaran diri dan tingkat ekonomi yang baik untuk menjaga kesehatan gigi dan mulut. ${ }^{30}$ Populasi dengan resiko tinggi cenderung tidak memiliki kesadaran diri untuk menjaga kesehatan gigi dan mulut sehingga belum ada dorongan dari masyarakat sendiri untuk rajin menggunakan pasta gigi berfluoride. ${ }^{33}$ Berdasarkan hal tersebut banyak peneliti yang lebih memilih menggunakan strategi intervensi 
kesehatan yang ditujukan kepada populasi untuk mengatasi permasalahan kesehatan tanpa menimbulkan adanya ketimpangan kesehatan secara menyeluruh. ${ }^{34}$

Penelitian yang dilakukan oleh Matsuyama dkk. menunjukkan bahwa S-FMR lebih efektif digunakan pada populasi dengan resiko tinggi dibandingkan dengan populasi dengan resiko rendah serta menunjukkan bahwa S-FMR mampu menurunkan ketimpangan prevalensi karies antar prefektur di Jepang. ${ }^{10}$ Indonesia juga telah melaksanakan intervensi kesehatan dengan pendekatan populasi salah satu contohnya adalah UKGS. Panduan UKGS yang diterbitkan oleh Kemenkes RI menyebutkan bahwa pilihan intervensi populasi yang dapat dilaksanakan adalah fluoridasi air minum dan pelaksanaan S-FMR. ${ }^{15}$

Program S-FMR atau berkumur dengan larutan $\mathrm{NaF}$ dilaporkan telah dilakukan di beberapa wilayah di Indonesia. Kegiatan UKGS PAUD Syakura Kids di Depok menerapkan program S-FMR pada siswa-siswi dengan berkumur menggunakan larutan $\mathrm{NaF} 0.2 \%$ rutin seminggu sekali selama 3 bulan. Larutan kumur $\mathrm{NaF}$ dibuat dengan mencampurkan 2 gram bubuk NaF dengan 1 liter air. ${ }^{13}$ Hasil dari program S-FMR tersebut mampu menurunkan resiko karies pada siswa siswi sebesar $20-50 \%$. Program berkumur larutan $\mathrm{NaF}$ juga telah dilakukan pada anak usia 5-6 tahun di Desa Wonokerto, Yogyakarta. Program tersebut dilakukan secara rutin selama beberapa bulan sebagai rangkaian dari kegiatan peningkatan kemampuan kader kesehatan gigi dan mulut Desa Wonokerto, Yogyakarta. Program berkumur larutan $\mathrm{NaF}$ tersebut menurunkan tingkat resiko karies pada anak yang mengikuti kegiatan. Hasil tersebut sesuai dengan penelitian oleh Matsuyama, dkk. yang menyatakan bahwa program berkumur dengan larutan $\mathrm{NaF}$ dapat menurunkan angka kejadian karies 30\%-35\%.10

Penelitian oleh Annisa dkk. menyatakan bahwa fluoride efektif ketika berada dalam rongga mulut dan tidak efektif setelah ditelan. Anak yang mengikuti program S-FMR diminta untuk mengukur kembali hasil kumur larutan $\mathrm{NaF}$ untuk mencegah adanya larutan yang tertelan. ${ }^{19}$ Larutan yang tertelan dalam dosis yang cukup banyak dapat menyebabkan terjadinya fluorosis gigi, apabila ada larutan yang tertelan setelahnya harus mengonsumsi susu untuk meminimalisir resiko terjadinya fluorosis gigi. ${ }^{8}$

Berkumur dengan larutan $\mathrm{NaF}$ akan meningkatkan efek remineralisasi dan meningkatkan kekerasan email. Larutan fluor pada gigi memiliki 3 mekanisme aksi kerja yaitu melalui peningkatan remineralisasi, pencegahan demineralisasi dan penghambatan glikolisis bakteri. Fluor bekerja dengan cara menghambat metabolisme bakteri plak yang dapat memfermentasi karbohidrat melalui perubahan hidroksil apatit pada enamel menjadi fluor apatit dan fluorapatit akan mempertinggi meneralisasi email dan membuat email lebih resisten terhadap serangan asam. ${ }^{20}$

Anak akan diminta tidak mengonsumsi apapun 30 menit setelah berkumur sehingga lebih banyak fluor yang tersimpan dalam saliva. Hasil penelitian oleh Darwita dkk. melaporkan bahwa retensi ion fluor dalam saliva setelah berkumur larutan fluor, sangat dipengaruhi oleh kecepatan alir saliva dan volume saliva sebelum atau sesudah penelanan. ${ }^{9}$ Keutamaan aksi fluor dalam rongga mulut adalah pada mekanisme aksi topikal, ketika ion fluor berada dalam saliva dengan konsentrasi yang optimal. Hal ini sesuai dengan pernyataan Annisa dan Ahmad bahwa semakin sedikit kontaminasi setelah berkumur, semakin baik keadaan fluor dalam saliva. ${ }^{19}$ 


\section{KESIMPULAN}

Pencegahan karies pada anak harus dilakukan sejak usia dini melalui berbagai program. Program S-FMR adalah salah satu pencegahan karies dengan memberikan flouride secara topikal pada anak usia sekolah. Sekolah dengan kriteria mayoritas siswa dengan prevalensi karies tinggi, tidak memiliki akses air minum berfluor, orang tua berpendapatan rendah, serta sulit mendapatkan akses ke fasilitas kesehatan merupakan sekolah yang diutamakan untuk melaksaanakan program SFMR. Pelaksanaan program S-FMR di sekolah menggunakan larutan fluoride dengan dosis rendah, cara sederhana, waktu pelaksanaan singkat, biaya yang relatif murah, serta pengawasan dapat dilakukan langsung oleh guru sekolah. Hasil program S-FMR dinilai efektif dalam menurunkan angka karies pada anak.

\section{REFERENSI}

1. Sicca C, Bobbio E, Quartuccio N, Nicolò G, Cistaro A. Prevention of dental caries: $A$ review of effective treatments. J Clin Exp Dent. 2016;8(5):e604-10.

2. Kementerian Kesehatan Republik Indonesia. Hasil Utama Riset Kesehatan Dasar 2018. Jakarta: Balai Penelitian Pengembangan Kementerian Kesehatan Rl; 2018.

3. Kementerian Kesehatan Republik Indonesia. Riset Kesehatan Dasar 2013. Jakarta: Balai Penelitian Pengembangan Kementerian Kesehatan RI; 2013.

4. Joseph J. Textbook of Preventive and Community Dentistry. Third Edit. New Delhi: CBS Publisher and Distributor Pvt Ltd; 2017.

5. Sumiok JB, Pangemanan DHC, Niwayan M. Gambaran Kadar Fluor Air Sumur Dengan Karies Gigi Anak Didesa Boyongpante Dua. Pharmacon. 2015;4(4):116-26.

6. O'Mullane DM, Baez RJ, Jones $\mathrm{S}$, Lennon MA, Petersen PE, Ruggunn AJ, et al. Fluoride and oral health. Comunity Dent Heal. 2016;33:69-99.

7. Horst JA, Tanzer JM, Milgrom PM. Fluorides and other preventive strategies for tooth decay. Dent Clin North Am.
2018;62(2):207-34.

8. Divaris K, Rozier RG, King RS. Effectiveness of a School-based Fluoride Mouthrinse Program. J Dent Res. 2012;91(3):282-7.

9. Darwita RR, Bahar A, Rahardjo A, Asri S. Retensi fluor di dalam saliva setelah program sikat gigi bersama pada siswa sekolah dasar. 2010;15(2):106-10.

10. Matsuyama Y, Aida J, Taura K, Kimoto K, Ando Y, Aoyama H, et al. School-based fluoride mouth-rinse program dissemination associated with decreasing dental caries inequalities between japanese prefectures: An ecological study. J Epidemiol. 2016;26(11):563-71.

11. Uwagawa $\mathrm{YN}$, Yoshihara A, Miyazaki $\mathrm{H}$. Long-term caries preventive effects of a school-based fluoride mouth rinse program in adulthood. Open Dent $\mathrm{J}$. 2011;5:24-8.

12. Komiyama E, Kimoto $\mathrm{K}$, Arakawa $\mathrm{H}$. Relationship between Duration of Fluoride Exposure in School-Based Fluoride Mouthrinsing and Effects on Prevention and Control of Dental Caries. ISRN Dent. 2012;2012(June 2005):1-8.

13. Chen C-A, Ling K, Esa R, Chia J, Eddy A, Yaw S. A school-based fluoride mouth rinsing programme in Sarawak: a 3-year field study. Community Dent Oral Epidemiol. 2010;38:310-4.

14. Ngatemi. Faktor Manajemen Pelaksanaan UKGS Dan Peran Orangtua Terhadap Status Kesehatan Gigi Dan Mulut Murid Sekolah Dasar. J Heal Qual. 2011;3(2):103-11.

15. Kementerian Kesehatan Republik Indonesia. Pedoman usaha kesehatan gigi sekolah (UKGS). Jakarta: Kementerian Kesehatan RI; 2012. 1-84 p.

16. Lendrawati. Penggunaan silver diamina fluorida ( $S D F$ ) $38 \%$ sebagai arresting caries treatment ( $A C T$ ) pada anak-anak. Maj Kedokt Andalas. 2011;35(2):98-105.

17. Buzalaf MAR, Pessan JP, Honorio HM, Cate JM ten. Mechanisms of action of fluoride for caries control. Monogr Oral Sci. 2011;22:97-114.

18. Martinez-Mier EA. Flouride: Its metabolism, toxicity, and role in dental health. J Evidence-Based Complement Altern Med. 2013;17(1):28-32.

19. Annisa, Ahmad I. Mekanisme fluor sebagai kontrol karies pada gigi anak. J Indones Dent Assoc. 2018;1(1):63-9.

20. Sirat NM. Pengaruh aplikasi topikal dengan larutan $\mathrm{NaF}$ dan SnF2 dalam pencegahan karies gigi. J Kesehat Gigi. 
2014;2(2):222-32.

21. Casamassimo PS, Fields HW, McTigue DJ, Nowak AJ. Pediatric Dentistry Infancy Through Adolescence. 5th ed. China: Elsevier; 2013. $144 \mathrm{p}$.

22. Harris NO, Garcia-Godoy F, Nathe CN. Primary Preventive Dentistry. Eight Edit. Boston: Pearson; 2014. 166 p.

23. Tashiro Y, Nakamura K, Seino K, Ochi S, Ishii $\mathrm{H}$, Hasegawa M. The impact of a school-based tooth-brushing program on dental caries: a cross- sectional study. Environ Health Prev Med. 2019;24(83):19.

24. Hiremath SS. Textbook of Public Health Dentistry. New Delhi: Elsevier; 2016. 323 p.

25. DivyaLalitha N, Rajmohan, Prabu D, Bharathwaj V, Manipal S. School based fluoride mouth rinse program and its effect on dental caries - A systematic review. Int J Pharmaeutical Sci adn Rev. 2019;58(1):154-7.

26. Chestnutt IG. Dental Public Health at a Glance. West Sussex: Wiley-Blackwell; 2016. $63 \mathrm{p}$.

27. Haque SE, Rahman $M$, Itsuko $K$, Mutahara M, Kayako S. Effect of a schoolbased oral health education in preventing untreated dental caries and increasing knowledge, attitude, and practices among adolescents in Bangladesh. Bio Med Cent Oral Heal. 2016;16(44):1-10.

28. Nowak AJ. Pediatric Dentistry Infancy Through Adolescence. Christensen JR, Marby TR, Townsend JA, Wells MH, editors. China: Elsevier; 2013. 163-164 p.

29. Marya CM. A Textbook of Public Health Dentistry. New Delhi: Jaypee Brothers Medical Publishers; 2011. 240-245 p.

30. Hutami MY, Himawati M, Widyasari R. Indeks karies gigi murid usia 12 tahun antara pendapatan orangtua rendah dan tinggi di SD Kota Cimahi. Padjajaran J Dent Res Students. 2017;2(2):1-6.

31. Faranitha $R$, Muhibat $S$, Suryanti N. Perbedaan indeks DMF-T antara siswa SMP di perkotaan dan perdesaan usia 12-13 tahun. J Kedokt Gigi Univ Padjadjaran. 2016;28(3).

32. Petersen PE, Kwan S. Equity, social determinants and public health programmes - The case of oral health. Community Dent Oral Epidemiol. 2011;39(6):481-7.

33. Jürgensen N, Petersen PE. Oral health behaviour of urban and semi-urban schoolchil- dren in the Lao PDR. Community Dent Health.
$2011 ; 28(4): 280-5$.

34. Lorenc T, Petticrew M, Welch V, Tugwell P. What types of interventions generate inequalities? evidence from systematic reviews. J Epidemiol Community Heal. 2012;67:8-11. 